\title{
The effects of maternal social phobia on mother-infant interactions and infant social responsiveness
}

Article

Accepted Version

Murray, L., Cooper, P., Creswell, C., Schofield, E. and Sack, C. (2007) The effects of maternal social phobia on mother-infant interactions and infant social responsiveness. Journal of Child Psychology and Psychiatry, 48 (1). pp. 45-52. ISSN 0021-9630 doi: https://doi.org/10.1111/j.1469-7610.2006.01657.x Available at https://centaur.reading.ac.uk/13915/

It is advisable to refer to the publisher's version if you intend to cite from the work. See Guidance on citing.

To link to this article DOI: http://dx.doi.org/10.1111/j.1469-7610.2006.01657.x

Publisher: Wiley

All outputs in CentAUR are protected by Intellectual Property Rights law, including copyright law. Copyright and IPR is retained by the creators or other copyright holders. Terms and conditions for use of this material are defined in the End User Agreement.

www.reading.ac.uk/centaur 
Central Archive at the University of Reading

Reading's research outputs online 


\title{
The effects of maternal social phobia on mother-infant interactions and infant social responsiveness
}

\author{
Lynne Murray, Peter Cooper, Cathy Creswell, Elizabeth Schofield, and \\ Caroline Sack
}

Winnicott Research Unit, School of Psychology, University of Reading, UK

\begin{abstract}
Background: Social phobia aggregates in families. The genetic contribution to intergenerational transmission is modest, and parenting is considered important. Research on the effects of social phobia on parenting has been subject to problems of small sample size, heterogeneity of samples and lack of specificity of observational frameworks. We addressed these problems in the current study. Methods: We assessed mothers with social phobia $(N=84)$ and control mothers $(N=89)$ at 10 weeks in face-to-face interactions with their infants, and during a social challenge, namely, engaging with a stranger. We also assessed mothers with generalised anxiety disorder (GAD) $(N=50)$. We examined the contribution to infant social responsiveness of early infant characteristics (neonatal irritability), as well as maternal behaviour. Results: Mothers with social phobia were no less sensitive to their infants during face-to-face interactions than control mothers, but when interacting with the stranger they appeared more anxious, engaged less with the stranger themselves, and were less encouraging of the infant's interaction with the stranger; infants of index mothers also showed reduced social responsiveness to the stranger. These differences did not apply to mothers with GAD and their infants. Regression analyses showed that the reduction in social responsiveness in infants of mothers with social phobia was predicted by neonatal irritability and the degree to which the mother encouraged the infant to interact with the stranger. Conclusions: Mothers with social phobia show specific parenting difficulties, and their infants show early signs of reduced social responsiveness that are related to both individual infant differences and a lack of maternal encouragement to engage in social interactions. Keywords: Anxiety, social phobia, parenting, mother-infant interactions, irritability. Abbreviations: GAD: generalised anxiety disorder.
\end{abstract}

Social phobia is a common disorder, affecting between $7 \%$ and $13 \%$ of individuals (Furmark, 2002). It is a persistent, disabling condition, at the extreme end of a continuum of social anxiety, in which the central psychopathological feature is an intense fear of scrutiny and negative evaluation by others, with a consequent avoidance of social encounters, and markedly restricted social functioning.

Social phobia aggregates in families, with children of affected parents being themselves at raised risk (Mancini, van Ameringen, Szatmari, Fugere, \& Boyle, 1996; Lieb et al., 2000). Notably, such aggregation shows specificity: first-degree relatives of individuals with social phobia are at increased risk for social phobia, but not other anxiety disorders (Fyer, Mannuzza, Chapman, Martin, \& Klein, 1995). While there is evidence for genetic mechanisms operating in intergenerational transmission, their contribution is modest (an estimated heritability of $10 \%$ (Nelson et al., 2000)), and environmental effects are likely to be significant. One important environmental influence is the quality of parenting. A number of dimensions have been considered relevant (Wood, McLeod, Sigman,

Conflict of interest statement: No conflicts declared.
Hwang, \& Chu, 2003). These include general characteristics, such as lack of warmth, as well as specific dimensions of over-protection and control that may limit children's opportunities to develop mastery and competence. Parents may also promote child anxiety by disengaging from potentially threatening situations, or by failing to encourage their children and promote their autonomy. In so doing, they may model fearful responses to the child, thereby enhancing the likelihood of child fearfulness. Notably, however, most studies of the role of parenting have concerned anxious adults retrospectively reporting on the parenting they received, or anxious children interacting with their parents. Such studies do not, therefore, directly address the question of the influence of parental anxiety disorder on parental behaviour and on child development. In fact, studies of anxious parents and their children, whether involving direct observations of parenting (Woodruff-Borden, Morrow, Bourland, \& Cambron, 2002; Turner, Beidel, Robertson-Nay, \& Tervo, 2003; Moore, Whaley, \& Sigman, 2004), or interview and questionnaire methods (Hirschfeld, Biederman, Brody, Faraone, \& Rosenbaum, 1997; Rubin, Nelson, Hastings, \& Asendorpf, 1999; McClure, Brennan, Hammen, \& 
Le Brocque, 2001; Lieb et al., 2000) have generally found little evidence for raised rates of parental rejection, over-control and over-protection; and where parental anxiety has been associated with such impairments, this has usually been in the context of difficult child characteristics (Moore et al., 2004; Hirschfeld et al., 1997; Rubin et al., 1999), suggesting that disturbances in child behaviour may elicit these parenting styles.

Few studies have examined the effects of adult anxiety on relationships with infants, and firm conclusions cannot be drawn. Feldman and colleagues (Feldman, Greenbaum, Mayes, \& Erlich, 1997) studied mothers and infants at three and nine months, measuring maternal trait anxiety at both times. Decreasing anxiety over time predicted increased maternal sensitivity, although maternal anxiety in this population was within the normal range. Weinberg and Tronick (1998) studied a small sample of mothers with panic disorder, depression or obsessive compulsive disorder. Index mothers were more disengaged and negative with their infants than controls but, as the authors note, the role of particular diagnoses is unclear. Similar difficulties of interpretation apply to the studies of Warren et al. (2003) and Field et al. (2005). In the former, mothers with panic disorder were found to be less sensitive than controls in early infancy, and less effective at disciplining at 14 months, but it would be premature to conclude that these effects resulted from the anxiety disorder, since index mothers commonly had other disorders, including depression. Similarly, Field and colleagues (2005) reported maternal withdrawal from the infant to be related to maternal anxiety, but since all the mothers in this study had co-morbid depression, it is not clear whether these findings can be generalised to mothers who experience anxiety alone.

Aside from the small sample sizes and problems concerning co-morbid depression, a particular difficulty of previous research has been the heterogeneity of diagnoses within the anxious groups themselves and the lack of specificity in the assessments. This is important because different anxiety disorders may have distinctive effects on parenting, rather than affecting performance across the board; and, in general, the observational frames used in research have been non-specific.

In the light of these considerations, we recruited a large sample of mothers with social phobia and their infants, and compared their behaviour with that of a non-anxious control group in a situation designed to elucidate index mothers' social difficulties, namely, having to converse with an unfamiliar person and manage their infant's engagement with the stranger. An important question was whether infants of index mothers showed signs of impaired social responsiveness, and whether such impairments were related to maternal social diffi- culties. Moreover, to assess whether any difficulties experienced by mothers and infants were specific to social phobia, we also observed a group with generalised anxiety disorder (GAD) in the absence of social phobia.

We also examined the contribution of infant characteristics. Genetic studies suggest that heritability of a general emotional vulnerability may confer risk for social phobia. Support for such a mechanism also derives from findings that behavioural inhibition, usually measured from late infancy, raises the risk of anxiety disorder, especially the social type (Turner, Beidel, \& Wolff, 1996; Hirschfeld et al., 1992; Biederman et al., 1993; Hayward, Killen, Kraemer, \& Taylor, 1998). Although the stability of such behaviour through infancy is not strong, one precursor comprises emotional and behavioural reactivity (Kagan \& Snidman, 1991). This measure, established for infants of four months, is conceptually closely related to that of neonatal irritability (Brazelton \& Nugent, 1995). Irritability is characterised by marked sensitivity to changes in the environment, with rapid escalation of distress and difficulty in regulating state to become calm again. In the current study, therefore, as well as investigating the effects of maternal diagnosis and maternal behaviour on infant social responsiveness, we assessed the role of neonatal irritability.

\section{Method}

\section{Sample}

Four thousand mothers attending routine 20-week antenatal scan clinics at the Royal Berkshire (UK) hospital completed screening questionnaires for social phobia and GAD. Five hundred and twenty-five high scoring women were re-contacted; of these, 154 (29.3\%) refused to participate in the study, and $67(12.8 \%)$ were found to be ineligible (e.g., because of moving away). The remaining 304 women were interviewed within the following month to confirm diagnosis. Of these, 139 (45.7\%) did not meet diagnostic criteria; 107 women were identified with social phobia, and 58 had GAD (but no social phobia). Fourteen of these women subsequently became ineligible for the study (e.g., due to premature delivery, infant death), 12 in the Social phobia group and 2 in the GAD group. A random sample of 164 women with low screening scores were also approached for participation as controls: $32(19.4 \%)$ refused to take part, and nine $(5.5 \%)$ were ineligible. The remaining 123 were interviewed to assess their mental state: 21 were excluded as they had disorders other than social phobia or $\mathrm{GAD}$, and seven became ineligible; one was diagnosed with social phobia and was therefore recruited into the social phobia group, bringing the total to 96; the remaining 94 women were recruited as controls on the basis of having no current or past social phobia or GAD. At 10 weeks postpartum, $84(87.5 \%)$ and $89(94.7 \%)$ of these mothers were assessed in the social phobia and control groups respectively, as were $50(87.7 \%)$ of mothers with GAD. 


\section{Procedure}

Neonatal irritability was assessed at 10 days in the home, in quiet conditions with low lighting. Mothers and infants then came to the University research rooms at 10 weeks. Following a settling-in period during which the study procedures were explained, mothers completed mental state questionnaires; at a point when the infant was alert and contented, mothers and infants were observed during a five-minute face-to-face interaction. A female researcher, who was unknown to the mother, then entered the room; she called the infant's name, and approached mother and infant; she paused to stand alongside the mother, spoke to the infant again, and then lifted the infant from their chair and tried to engage him/her in social interaction. The stranger episode lasted $21 / 2$ minutes. Both episodes were videotaped throughout. Two researchers scored the mother-infant interactions, and two other researchers scored the stranger-mother-infant episodes; all were unaware of maternal diagnosis.

\section{Measures}

Maternal mental state. Screening questionnaires: An eight-item version of the Social Interaction and Anxiety Scale and the Social Phobia Scale (SIAS and SPS; Mattick \& Clarke, 1998), and a five-item version of the Penn State Worry Questionnaire (PSWQ; Meyer, Miller, Metzger, \& Borkovec, 1990) were used. Items were included on the basis of their high factor loadings on these measures. A pilot of each screen identified cut-off scores for the top $10 \%$ of respondents. ${ }^{1}$ Full versions of the questionnaires were completed at the 10 week assessment.

Diagnostic Interview: Mothers were interviewed with the Structured Clinical Interview for DSM-IV Axis 1 disorders (SCID-1; First et al., 1995) by trained psychologists and mental health clinicians. All interviews were subsequently discussed with a senior clinical team to confirm diagnosis and assignment to the three study groups. The rate of concurrent major depressive disorder was low for all groups: $7.1 \%$ for those with social phobia, $5.2 \%$ for those with GAD, and $1.1 \%$ for those in the control group.

Infant behavioural characteristics. The Neonatal Behavioural Assessment Scale (Brazelton \& Nugent, 1995) was administered by trained psychologists to identify infant irritability. ${ }^{2}$ This scale has been widely used, and has good reliability and validity. We used the items 'peak of excitement', 'rapidity of build up' and 'irritability' collectively to define infants as irritable (Cronbach's alpha $=.83$ ) if the mean score was six or over, a standard method used in research (e.g., Crockenberg, 1981; van den Boom, 1994, Murray, Stanley, Hooper, King, \& Fiori-Cowley, 1996a).

Mother-infant interactions. These were scored using five-point scales previously found to distinguish a

\footnotetext{
Contact Peter Cooper for details.

${ }^{2}$ Joanna Hawthorne, of the Cambridge Brazelton Centre, provided training and confirmed reliability.
}

number of other maternal disorders, as well as different infant populations (Murray et al., 1996a; Murray, FioriCowley, Hooper, \& Cooper, 1996b; Gunning et al., 2004). Maternal behaviour was characterised on dimensions of sensitivity (warmth, acceptance, responsiveness, non-demanding and overall sensitivity scales), active engagement (verbal and non-verbal), and expressed anxiety (e.g., biting lip, tense posture, worried expression). Infants were rated on the dimensions of positive communication (attention to mother, vocal and behavioural expressiveness), and distress (crying and fretfulness).

Mother-stranger-infant interactions. These were similarly scored on five-point scales, some being devised specifically for this study. Maternal dimensions comprised the degree of engagement with the stranger (greeting, making eye contact, smiling, conversing), control of the infant-stranger interaction (e.g., speaking to the stranger on the infant's behalf, touching the infant during the stranger-infant interaction), encouragement to the infant to interact with the stranger (e.g., making positive comments, making encouraging facial expressions and gestures), and expressed anxiety (as for the mother-infant interaction). Infant behaviour during this episode was scored on three dimensions: degree of attention to mother, positive communication with the stranger and distress (the last two being defined as for the mother-infant engagement).

A random sample of 20 videotapes were scored by the same researchers to establish reliability. Intra-class correlations were, for maternal behaviour with the infant, mean $=.81$, range $=.75-.86$, infant behaviour with the mother, mean $=.90$, range $.79-.96$, maternal behaviour in the stranger episode, mean $=.86$, range .78-.94, and infant behaviour in the stranger episode, mean $=.89$, range $.82-.94$.

\section{Data analysis}

Comparisons between the behaviour of mothers and infants in the social phobia and control groups were made using $t$-tests where variables were normally distributed and chi square tests for binary variables. Where significant differences were identified, comparisons were made between the GAD and control groups to see if such effects were specific to social phobia or a function of more general anxiety. We used correlational analyses to explore the relationship of neonatal irritability to 10 -week infant behaviour with the stranger, and to examine the relation between the mother's behaviour with the infant during the episode with the stranger and the infant's response. Since infant irritability may have made the infant vulnerable to the impact of maternal social phobia, we also examined the effects of the interaction between irritability and both maternal group and the mother's management of the infant during the episode with the stranger, using ANOVA and binary logistic regression, as appropriate. The contribution of early infant irritability and maternal behaviour to any differences between the social phobia and control groups in infants' response to the stranger was then examined in regression analyses. Since male and female infants have been found to differ in their 
response to maternal depression, we also investigated whether infant sex affected infant behaviour. Finally, since previous studies have found depression to cooccur with anxiety, thus confounding the interpretation of findings, the analyses were repeated, excluding any mothers with major depression.

\section{Results}

The characteristics of mothers and infants are shown in Table 1. The three study groups were demographically similar, although a few more mothers from the GAD group were not Caucasian. Most mothers were married or cohabiting, and were from middle-upper class families. Scores on the Social Phobia and GAD screening questionnaires for those who declined to participate did not differ from those of women who were recruited: for the Social Phobia screen, scores were, respectively, 23.05 $(\mathrm{SD}=4.05)$ and $22.74(\mathrm{SD}=4.55)(t=.61, \mathrm{NS})$; and for the GAD screen, they were $18.02(\mathrm{SD}=2.77)$ and $18.21(\mathrm{SD}=2.18),(t=.59, \mathrm{NS})$. Scores on the SIAS and SPS at 10 weeks showed that women in the social phobia group continued to show clinically significant levels of symptoms, distinguishing them from both the control and GAD group mothers.

\section{Mother-infant and mother-stranger-infant interactions}

All scales for the mother-infant interactions were normally distributed, as were maternal anxiety and encouragement in the stranger episode; the remaining variables were skewed and were therefore dichotomised.

\section{Interaction differences between social phobia and control groups}

As can be seen from Table 2, when interacting with their infants mothers with social phobia were more anxious than control mothers, and they were also less actively engaged; they were, however, similar to controls in terms of their general sensitivity. There were no differences between the two groups of infants in terms of the degree to which they were positively engaged with their mother, or were distressed.

During the episode with the stranger, mothers with social phobia were again more anxious than control group mothers, and they were also less likely to engage with the stranger. With regard to the management of the infant during this episode, mothers with social phobia were less encouraging of their infants' interaction with the stranger, but they were no more likely to try to control the strangerinfant engagement. As in the mother-infant interaction, the two groups of infants showed no difference in their degree of distress; nevertheless, infants of index mothers tended to be more likely to remain attentive to their mother while the stranger was present, and they were significantly less likely to communicate positively with the stranger when she attempted to interact with them.

There were no differences between boys' and girls' behaviour on any dimension, and therefore infant sex was not considered further.

\section{Specificity of interaction differences}

We assessed whether the features of the social phobia group which distinguished them from controls also characterised mothers with GAD and their infants. In the mother-infant interaction, mothers with GAD were not significantly more anxious than control mothers (GAD mean $=3.1$, $\mathrm{SD}=1.3$, vs. control mean $2.7, \mathrm{SD}=1.2, t(134)=$ 1.65), but, as for mothers with social phobia, they were significantly less actively engaged with their infants than controls (GAD mean $=2.3, \mathrm{SD}=.8$ vs. control mean $2.6, \mathrm{SD}=.9, t(134)=2.17, p=$ .03). During the stranger episode, by contrast, where mothers with social phobia differed from controls on three of the four dimensions assessed, mothers with GAD were indistinguishable from

Table 1 Characteristics of sample

\begin{tabular}{|c|c|c|c|}
\hline & \multicolumn{3}{|c|}{ Mean (SD) } \\
\hline & Control $(N=94)$ & Social phobia $(N=96)$ & $\operatorname{GAD}(N=56)$ \\
\hline Mother's age (years) & $31.2(4.16)$ & $30.4(5.07)$ & 30.7 (3.64) \\
\hline Birthweight (gm) & 3505 (477) & $3520(411)$ & 3483 (507) \\
\hline SIAS 10 weeks & $12.7(7.8)$ & 42.0 (10.4) xxxa) xxxb) & $19.6(11.9)$ \\
\hline & N (\%) & $\mathrm{N}(\%)$ & N (\%) \\
\hline Male & $47(50)$ & 38 (39.6) & $26(46.4)$ \\
\hline Low SES & $7(7.4)$ & $16(16.7)$ & $3(5.4)$ \\
\hline Ethnicity-Caucasian & $89(94.7)$ & $96(100)$ & $48(85.7)$ \\
\hline Married/cohabiting & $90(95.7)$ & $89(92.7)$ & $54(96.4)$ \\
\hline
\end{tabular}

$\mathrm{xxxa}) p<.001$ social phobia vs. control group.

$\mathrm{xxxb}) p<.001$ social phobia vs. GAD group. 
Table 2 Comparisons of maternal and infant behaviour during interactions in social phobia and control groups

\begin{tabular}{|c|c|c|c|}
\hline & Social phobia $(N=84)$ & Control $(N=89)$ & t-test/chi square \\
\hline \multicolumn{4}{|l|}{ Mother-infant interaction } \\
\hline \multicolumn{4}{|l|}{ Maternal behaviour } \\
\hline Sensitivity & $3.2(.7)$ & $3.3(.7)$ & $t(168)=1.20, \mathrm{NS}$ \\
\hline Active engagement & $2.4(.8)$ & $2.6(.9)$ & $t(168)=2.32, p=.02$ \\
\hline \multicolumn{4}{|l|}{ Infant behaviour } \\
\hline Positive communication & $2.9(1.1)$ & $2.9(1.0)$ & $t(168)=.07, \mathrm{NS}$ \\
\hline Distress & $2.3(1.0)$ & $2.2(.9)$ & $t(168)=.28, \mathrm{NS}$ \\
\hline \multicolumn{4}{|l|}{ Stranger episode } \\
\hline \multicolumn{4}{|l|}{ Maternal behaviour } \\
\hline Anxiety & $3.2(.9)$ & $2.8(.8)$ & $t(166)=2.60, p=.01$ \\
\hline Engagement with stranger & $14(17.3 \%)$ & $32(36.4 \%)$ & $\chi^{2}(1)=7.75, p=.005$ \\
\hline Control & $30(37.0 \%)$ & $34(38.6 \%)$ & $\chi^{2}(1)=.046, \mathrm{NS}$ \\
\hline Encouragement & $2.2(1.0)$ & $2.5(.9)$ & $t(166)=2.30, p=.02$ \\
\hline \multicolumn{4}{|l|}{ Infant behaviour } \\
\hline Positive with stranger & $12(14.8 \%)$ & $24(27.3 \%)$ & $\chi^{2}(1)=3.91, p=.048$ \\
\hline Distress & $2.8(.8)$ & $2.6(.7)$ & $t(167)=1.29, \mathrm{NS}$ \\
\hline
\end{tabular}

controls (for expressed anxiety GAD mean $=2.9$, $\mathrm{SD}=.9$ vs. control mean $2.8, \mathrm{SD} .8, t(135)=.69$ for engagement with the stranger, $32 \%$ showed this behaviour in the GAD group vs. $36 \%$ in the controls, $\chi^{2}(1)=.27$; and for encouragement of the infant's interaction with the stranger, the GAD mean was $2.3 \mathrm{SD}=1.0$ vs. control mean $=2.5$ $\mathrm{SD}=.9, t(135)=.92)$. Similarly, in terms of positive engagement with the stranger, infants of GAD mothers were comparable to controls (GAD 28\% vs. control $\left.27.3 \%, \chi^{2} t(1)=.01\right)$.

\section{Prediction of reduced infant responsiveness}

Having established that infants of mothers with social phobia were less likely than control group infants to engage positively with the stranger, and that this difference was specific to their mother having social phobia, we then proceeded, using correlational analyses, to explore the possible basis for this difference in terms of the distinctive features of maternal behaviour during the stranger episode and in terms of the infant's own characteristics. Since directional predictions were made, one-tailed tests were used. Maternal encouragement of the infant's interaction with the stranger was associated with more positive infant responsiveness $\left(\mathrm{r}_{\mathrm{b}}(168)=.18, p<.01\right)$, but the level of expressed anxiety and the degree of maternal engagement with the stranger were unrelated to the infant's response $\left(\mathrm{r}_{\mathrm{b}}(168)=-.07\right.$, and phi $(169)=$ .07 , respectively). With regard to neonatal behaviour, we first compared the rate of irritability in the social phobia and control groups. This applied to $16(20 \%)$ neonates in the social phobia group, and $10(11.5 \%)$ control group infants, a difference that was not significant $\left(\chi^{2}(1)=2.29\right)$. We then examined the correlation between neonatal irritability and infant responsiveness to the stranger. As expected, infants who were classified as irritable as neonates were less likely to engage positively with the stranger at 10 weeks than non-irritable infants (phi $(167)=-.15, \quad p<.05)$. We then investigated whether irritability may have made the infant more vulnerable to the effects of maternal social phobia, examining the effects on infant responsiveness to the stranger of interactions between irritability and both maternal group and the mother's behaviour during the stranger episode. None of these was significant.

In a final analysis, we used logistic regression to address the question of whether the effect of maternal social phobia on the infant's response to the stranger still held when taking into account neonatal irritability and the mother's encouragement of the infant's interaction with the stranger. As can be seen in Table 3, whereas the effect of maternal group was significant when considered alone in the first step, when infant irritability and maternal encouragement were included, the effect of maternal social phobia was reduced.

All analyses reported above were repeated excluding women with depression; this did not affect the pattern of findings.

Table 3 Regression analyses showing effect of maternal social phobia on infant social responsiveness, alone (step 1), and including neonatal behaviour and maternal encouragement (step 2)

\begin{tabular}{lllllr}
\hline & & & & \multicolumn{2}{c}{$95 \%$ CI } \\
\cline { 5 - 6 } & Wald & Sig & Odds ratio & Upper & Lower \\
\hline Step 1 & & & & & \\
$\quad$ Group & 3.08 & .05 & 2.2 & 1.0 & 4.7 \\
$\begin{array}{l}\text { Step 2 } \\
\quad \text { Irritability }\end{array}$ & 2.28 & .10 & 3.6 & .8 & 16.3 \\
$\quad \begin{array}{l}\text { Maternal } \\
\quad \text { encouragement }\end{array}$ & 2.38 & .12 & 1.4 & .9 & 2.1 \\
$\quad$ Group & 2.77 & .13 & 1.8 & .8 & 4.1 \\
\hline
\end{tabular}




\section{Discussion}

Much previous research on the effects of maternal anxiety disorder on parenting has been subject to methodological difficulties, including sample heterogeneity, lack of specificity of observational frames, and small sample sizes. We addressed these problems by recruiting a large, diagnostically homogeneous, community sample of mothers with social phobia, and observed them in a situation designed to elucidate social anxiety. In order to address the question of specificity of effects, we also assessed a group of mothers with GAD, but no social phobia, and their infants. Finally, we aimed to assess the contribution of infant characteristics by making objective infant assessments within a prospective, longitudinal design.

A number of findings were notable. First, there was no evidence for general parenting deficits in mothers with social phobia. Thus, although these mothers appeared to be more anxious and somewhat more withdrawn than control mothers when interacting with their children, they showed no deficits in terms of their general sensitivity to the infant, and they were no more controlling than non-anxious mothers. Given this, it was not surprising that these mothers' infants were no more distressed than control group infants and engaged in positive communication with their mothers to the same extent. These findings are consistent with those of a number of other studies of anxious parents, where normal levels of warmth, acceptance and control have been documented (Lieb et al., 2000; McClure et al., 2001; Woodruff-Borden et al., 2002; Turner et al., 2003; Moore et al., 2004), in spite of somewhat reduced levels of engagement (Woodruff-Borden et al., 2002; Turner et al., 2003). Notably, these findings differ markedly from studies of depressed mothers, where impairments appear more pervasive, and the impact on the infant correspondingly more marked (Murray \& Cooper, 2003).

As predicted, mothers with social phobia had particular difficulties in the context of a social challenge, that is, having to converse with a stranger and observe their infant in interaction with the stranger. In this situation, not only did socially phobic mothers appear more anxious and fail to engage with the stranger, but they were also significantly less encouraging of their infant's engagement with the stranger; in turn, their infants tended to remain attentive to their mother during the period when the stranger sought to interact with them, and were less likely to communicate positively with the stranger. In sum, while the effects on the infant were not strong, the findings suggest that infants of mothers with social phobia may show early signs of reduced social responsiveness.

The findings for mothers with social phobia contrasted with those for mothers with GAD, suggesting anxiety subgroup-specific effects. These were particularly evident in the context of the social challenge where, unlike mothers with social phobia, those with GAD were indistinguishable from control group mothers in terms of manifest anxiety, engagement with the stranger, and encouragement of their infants. Similarly, their infants did not show the pattern of reduced social responsiveness shown by those of mothers with social phobia. This underlines the importance of taking into account different diagnostic groupings, and of constructing situations for research that are specific to the disorder in question, if parenting difficulties associated with the disorder are to be elucidated.

We attempted to investigate the sources of the reduced infant social responsiveness associated with maternal social phobia. There was some evidence that infant characteristics may be important. Neonatal irritability was present in almost twice as many infants of social phobia mothers as control mothers and, although this difference was not statistically significant, it did appear that this infant behavioural constellation influenced infant responsiveness to the stranger. This finding is consistent with those of a number of other studies that have highlighted the importance of infant and child characteristics, both as they affect parental behaviour to bring about maladaptive patterns of responding (Cutrona \& Troutman, 1986; Murray et al., 1996a), and as early precursors of later social anxiety. Whether the association between neonatal irritability and reduced social responsiveness involves the genetic mechanisms that have so far been identified in relation to social phobia and other affective disorders, or the possible impact of maternal antenatal anxiety on the foetus (Glover \& O'Connor, 2002), is unclear.

Maternal behaviour also appeared important in influencing infant social responsiveness, and particularly the extent to which the mother encouraged her infant to engage socially with the stranger. Control mothers would typically use a warm, reassuring tone, and invite their infant to interact with the stranger, often marking this message in a stereotypical fashion, with clear eyebrow flashes, smiles and nods of the head, whereas mothers with social phobia would more often avert their gaze and remain motionless. The mechanisms underlying the link between these maternal behaviours and infant responsiveness are unclear. At 10 weeks it is unlikely that any process of 'social referencing' is occurring, whereby infants actively solicit information from others to guide their behaviour in response to ambiguous or novel situations (see review by Feinman, Roberts, Hsieh, Sawyer, \& Swanson, 1992). Thus, while our previous work has shown that this mechanism is indeed important in the context of infant responses to unfamiliar adults (de Rosnay, Cooper, Tsigaras, \& Murray, in press), such effects have not been demonstrated until around nine months. On the other hand, a large body of evidence has accumulated showing infants to be highly sensitive to many parameters of adult 
communication in the first few months, including voice quality, direction of gaze, the degree of contingency, and facial expressions of emotion (Trevarthen \& Aitken, 2001). Mothers modulate these behaviours on a moment-to-moment basis to maintain their infant's engagement and regulate their affect (Tronick \& Gianino, 1986). It is possible that the reduced social responsiveness to the stranger on the part of infants of mothers with social phobia arose as a consequence of the attenuation of these regulatory maternal behaviours, as the socially phobic mothers became more withdrawn and less encouraging in the presence of the stranger.

The longer-term consequences of the early behaviour towards the stranger we observed in infants of mothers with social phobia are unclear. It is important to note that we did not observe frank avoidance or distress, but rather a reduction in normal positive responsiveness. Whether such behaviour is a precursor of later frank, socially anxious behaviour remains to be investigated.

\section{Acknowledgements}

This work was supported by a programme grant from the Medical Research Council (UK) (ref G9324094), and by the Health Foundation. We are grateful to Melanie Royal-Lawson, Rachel Kelly, Monika Parkinson, Sheila Summers, Paula Liberton, Susan Campbell, Joanna Pearson and Daniele Serveri for assistance, variously, with recruitment and assessment of study subjects, and coding of interaction data. We thank Joanna Hawthorne for training on assessment of neonatal behaviour.

\section{Correspondence to}

Lynne Murray, Winnicott Research Unit, School of Psychology, University of Reading, Reading RG6 6AL, UK; Tel: 0118 3786302; Fax: 0118 3786665; Email: lynne.murray@rdg.ac.uk

\section{References}

Biederman, J., Rosenbaum, J.F., Bolduc-Murphy, E.A., Faraone, S.V., Chaloff, J., Hirschfeld, D.R., \& Kagan, J. (1993). A 3-year follow-up of children with and without behavioral inhibition. Journal of the American Academy of Child and Adolescent Psychiatry, 32, 814-821.

Brazelton, T.B., \& Nugent, J.K. (1995). The neonatal behaviour assessment scale. London: MacKeith Press.

Crockenberg, S.B. (1981). Infant irritability, mother responsiveness, and social support influences on the security of infant-mother attachment. Child Development, 52, 857-865.

Cutrona, C.E., \& Troutman, B.R. (1986). Social support, infant temperament, and parenting self-efficacy:
A mediational model of postpartum depression. Child Development, 57, 1507-1518.

de Rosnay, M., Cooper, P.J., Tsigaras, N., \& Murray, L. (in press). Transmission of social anxiety from mother to infant: An experimental study using a social referencing paradigm. Behaviour Research and Therapy.

Feinman, S., Roberts, D., Hsieh, K., Sawyer, D., \& Swanson, D. (1992). A critical review of social referencing in infancy. In S. Feinman (Ed.), Social referencing and the social construction of reality in infancy (pp. 15-54). Plenum Press: New York .

Feldman, R., Greenbaum, C.W., Mayes, LC., \& Erlich, S.H. (1997). Change in the mother-infant interactive behavior: Relations to the change in the mother, the infant, and the social context. Infant Behavior and Development, 20, 151-163.

Field, T., Hernandez-Reif, M., Vera, Y., Gil, K., Diego, M., Bendall, D., \& Yando, R. (2005). Anxiety and anger effects on depressed mother-infant spontaneous and imitative interactions. Infant Behavior and Development, 28, 1-9.

First, M.B., Spitzer, R.L., Gibbon, M., et al. (1995). Structured Clinical Interview for DSM-IV Axis I Diagnoses. New York: New York State Psychiatric Institute, Biometrics Research Department.

Furmark, T. (2002). Social phobia: Overview of community surveys. Acta Psychiatrica Scandinavia, 105, 84-93.

Fyer, A.J., Mannuzza, S., Chapman, T.F., Martin, L.Y., \& Klein, D.F. (1995). Specificity in familial aggregation of phobic disorders. Archives of General Psychiatry, 52, 564-573.

Glover, V., \& O'Connor, T.G. (2002). Effects of antenatal anxiety: Implications for development and psychiatry. British Journal of Psychiatry, 180, 389391.

Gunning, M., Conroy, S., Valoriani, V., Figueiredo, B., Kammerer, M.H., Muzik, M., Glatigny-Dallay, E., \& Murray, L. (2004). Measurement of mother-infant interactions and the home environment in a European setting: Preliminary results from a crosscultural study. British Journal of Psychiatry, 46 (Suppl.), s38-44.

Hayward, C., Killen, J.D., Kraemer, H.C., \& Taylor, C.B. (1998). Linking self-reported childhood behavioral inhibition to adolescent social phobia. Journal of the American Academy of Child and Adolescent Psychiatry, 37, 1308-1316.

Hirschfeld, D., Biederman, J., Brody, L., Faraone, S.V., \& Rosenbaum, J.F. (1997). Expressed emotion toward children with behavioral inhibition: Associations with maternal anxiety disorder. Journal of the American Academy of Child and Adolescent Psychiatry, 36, 910-917.

Hirschfeld, D.R., Rosenbaum, J.F., Biederman, J., et al. (1992). Stable behavioural inhibition and its association with anxiety disorder. Journal of the American Academy of Child and Adolescent Psychiatry, 31, 103-111.

Kagan, J., \& Snidman, N. (1991). Infant predictors of inhibited and uninhibited profiles. Psychological Science, 2, 40-44.

Lieb, R., Wittchen, H.U., Hofler, M., Fuetsch, M., Stein, M.B., \& Merikangas, K.R. (2000). Parental psychopathology, parenting styles, and the risk of social 
phobia in offspring: A prospective-longitudinal community study. Archives of General Psychiatry, 57, 859-866.

Mancini, C., van Ameringen, M., Szatmari, P., Fugere, C., \& Boyle, M. (1996). A high-risk pilot study of the children of adults with social phobia. Journal of the American Academy of Child and Adolescent Psychiatry, 35, 1511-1517.

Mattick, R.P., \& Clarke, J.C. (1998). Development and validation of measures of social phobia scrutiny fear and social interaction anxiety. Behaviour Research and Therapy, 36, 455-470.

McClure, E.B., Brennan, P.A., Hammen, C., \& Le Brocque, R.M. (2001). Parental anxiety disorders, child anxiety disorders, and the perceived parentchild relationship in an Australian high-risk sample. Journal of Abnormal Child Psychology, 29, 1-10.

Meyer, T.J., Miller, M.L., Metzger, R.L., \& Borkovec, T.D. (1990). Development and validation of the Penn State Worry Questionnaire. Behaviour Research and Therapy, 28, 487-495.

Moore, P.S., Whaley, S.E., \& Sigman, M. (2004). Interactions between mothers and children: Impacts of maternal and child anxiety. Journal of Abnormal Psychology, 113, 471-476.

Murray, L., \& Cooper, P.J. (2003). Intergenerational transmission of affective and cognitive processes associated with depression: Infancy and preschool years. In I. Goodyer (Ed.), Unipolar depression: $A$ lifespan perspective (pp. 17-46). Cambridge: Cambridge University Press.

Murray, L., Fiori-Cowley, A., Hooper, R., \& Cooper, P.J. (1996b). The impact of postnatal depression and associated adversity on early mother-infant interactions and later infant outcome. Child Development, 67, 2512-2526.

Murray, L., Stanley, C., Hooper, R., King, F., \& FioriCowley, A. (1996a). The role of infant factors in postnatal depression and mother-infant interactions. Developmental Medicine and Child Neurology, 38, 109-119.

Nelson, E.C., Grant, J.D., Buchollz, K.K., Glowinski, A., Madden, P.A.F., Reich, W., \& Heath, A.C. (2000). Social phobia in a population-based female adolescent twin sample: Comorbidity and associated suicide related symptoms. Psychological Medicine, 30, 797804.
Rubin, K., Nelson, L., Hastings, P., \& Asendorpf, J. (1999). The transaction between parents' perceptions of their children's shyness and their parenting styles. International Journal of Behavioral Development, 23, 937-957.

Trevarthen, C.B., \& Aitken, K.J. (2001). Infant intersubjectivity: Research, theory and clinical application. Journal of Child Psychology and Psychiatry, 42, 3-49.

Tronick, E.Z., \& Gianino, A. (1986). The transmission of maternal disturbance to the infant. In E.Z. Tronick \& T. Field (Eds.), Maternal depression and infant disturbance (pp. 61-82). San Francisco: Jossey-Bass.

Turner, S.M., Beidel, D.C., Robertson-Nay, R., \& Tervo, K. (2003). Parenting behaviors in parents with anxiety disorders. Behaviour, Research and Therapy, 41, 541-554.

Turner, S.M., Beidel, D.C., \& Wolff, P.L. (1996). Is behavioural inhibition related to the anxiety disorders? Clinical Psychology Review, 16, 157-172.

Van den Boom, D.C. (1994). The influence of temperament and mothering on attachment and exploration: An experimental manipulation of sensitive responsiveness among lower-class mothers with irritable infants. Child Development, 65, 1457-1477.

Warren, S.L., Gunnar, M.R., Kagan, J., Anders, T.F., Simmens, S.J., Rones, M., Wease, S., Aron, E., Dahl, R.E., \& Sroufe, L.A. (2003). Maternal panic disorder: Infant temperament, neurophysiology, and parenting behaviors. Journal of the American Academy of Child and Adolescent Psychiatry, 42, 814-825.

Weinberg, M.K., \& Tronick, E.Z. (1998). The impact of maternal psychiatric illness on infant development. Journal of Clinical Psychiatry, 59(Suppl. 2), 53-61.

Wood, J.J., McLeod, B.D., Sigman, M., Hwang, W.C., \& Chu, B.C. (2003). Parenting and childhood anxiety: Theory, empirical findings, and future directions. Journal of Child Psychology and Psychiatry, 44, 134-151.

Woodruff-Borden, J., Morrow, C., Bourland, S., \& Cambron, S. (2002). The behavior of anxious parents: Examining mechanisms of transmission of anxiety from parent to child. Journal of Clinical Child and Adolescent Psychology, 31, 364-374.

Manuscript accepted 27 April 2006 